\title{
Doctor Consultation through Mobile Applications in India: An Overview, Challenges and the Way Forward
}

\author{
Neeraj Agarwal, Bijit Biswas \\ Department of Community and Family Medicine, All India Institute of Medical Sciences, Patna, India
}

Objectives: To layout mHealth (mobile health) applications operating in India with the facility of either online doctor consultation or offline doctor appointment booking. Methods: A cross-sectional, observational and web-based study was conducted. We searched the Google Play Store with the search strategy "health apps in India". In the results, 250 applications (apps) appeared. Out of 250 apps, finally, 22 apps were found to be providing online doctor consultation and/or doctor appointment booking-related services. Results: Among the selected mHealth apps operating in India and providing doctor consultationrelated services online/offline, Practo, mfine, DocsApp, 1mg, Netmeds, Lybrate, MediBuddy, and Medlife were found to be the eight most popular ones with over a million downloads and on average four-plus user rating out of five. Practo, mfine, and Lybrate offer doctor consultation through chat, audio, and video calling. Netmeds and DocsApp offer doctor consultation through both chat and audio call. 1mg offers free chat consultation, while MediBuddy and Medlife offer audio call consultation only. Considering booking doctor appointments for offline consultation, Practo, mfine, 1mg, and Lybrate only offer this facility among the eight most popular selected mHealth apps. Conclusions: mHealth apps providing doctor consultation are gaining popularity in India, and they have enormous potential in the country. The government should make enabling policies to facilitate and popularise mHealth apps.

Keywords: Telemedicine, Mobile Applications, Referral and Consultation, Appointments and Schedules, Delivery of Health Care

Submitted: February 12, 2020

Revised: March 12, 2020

Accepted: March 17, 2020

\section{Corresponding Author}

Bijit Biswas

Department of Community and Family Medicine, All India Institute of Medical Sciences, Phulwarisharif, Patna 801507, Bihar, India. Tel: +917003881125, E-mail: drbijitbiswas@gmail.com (https://orcid. org/0000-0002-8526-0164)

This is an Open Access article distributed under the terms of the Creative Commons Attribution Non-Commercial License (http://creativecommons.org/licenses/by$\mathrm{nc} / 4.0 /$ ) which permits unrestricted non-commercial use, distribution, and reproduction in any medium, provided the original work is properly cited.

(c) 2020 The Korean Society of Medical Informatics

\section{Introduction}

mHealth (mobile health) is one of the components of eHealth. The Global Observatory for eHealth (GOe) defined mHealth as medical and public health practice supported by mobile devices, such as mobile phones, patient monitoring devices, personal digital assistants (PDAs), and other wireless devices. In mHealth, mobile phones and their various utilities are utilised and capitalised upon. The various utilities of a mobile phone are voice calls, short messaging service (SMS), mobile applications (apps), Internet, global positioning system (GPS), Bluetooth technology etc. [1,2].

Globally, there are over 7 billion wireless subscribers, and about 3.9 billion (51.2\%) have access to the Internet [3]. In 
terms of the wireless communication subscriber base, India is second in the world following China with 1,165.5 million mobile phone subscribers in the country (as on June 30,2019 ). The teledensity of India is 88.5 (urban, 156.4; rural, 56.7). There were approximately 578.2 million wireless data subscribers in India at the end of 2018, which is $36.3 \%$ higher than in 2017 (424.02 million) and 205.4\% higher than in 2014 (281.5 million). The volume of average wireless data usage per wireless data subscriber per month has also increased by $185.4 \%$ (from 4.1 GB during the year 2017 to 7.7 GB during the year 2018) [4]. This makes the prospect of mHealth in the country higher than ever.

Mobile health technologies are a proven medium of doctorpatient communication and have contributed to significant improvement in the patients' health outcomes $[5,6]$. Doctor consultation through mobile health apps is convenient for the doctors and their patients as it saves time and money of both [7-12]. This approach has been found to overcome widespread health system barriers, such as health professional shortages, reliance on untrained and/or informal providers, cost of service, transportation, and lack of sources of reliable information $[8,9,13]$. In India, the dominant mode of healthcare financing is out of pocket expenditure, and the majority of healthcare is delivered by the private sector [14]. Thus, mHealth, as a proven medium of healthcare delivery, has enormous potential in the country. With urbanisation, the demand for mHealth-related services in the country is likely to increase too [15]. To our knowledge, there has been very little published work in the domain of mHealth applications currently functioning in the country with the provision of doctor consultation online/offline. With this background, the current research is being formulated to overview the mHealth apps operating in India with the facility of either online doctor consultation or offline doctor appointment booking.

\section{Case Description}

\section{Process of Selection of $\mathrm{mHealth}$ Applications}

A cross-sectional, observational, and web-based study was conducted. Those apps that were providing either online doctor consultation or doctor appointment booking-related services and operating in India were included, while others were excluded. We searched the Google Play Store with the search strategy "health apps in India". In the results, 250 apps appeared. Out of 250 apps, finally, 22 apps were found to be providing online doctor consultation and/or doctor appointment booking-related services, so they were included in the study. The selection of mobile apps is presented in detail in Figure 1. The data retrieved from the Google Play Store were analysed and represented using Microsoft Excel and Word 2016.

\section{Results}

All the selected mHealth apps were providing online doctor consultation-related services, with the CallDoc App only providing offline doctor appointment booking-related services. Similarly, doctor appointment booking facility was only provided by Practo, mfine, Lybrate, Ask Apollo, I Online Doctor, CallDoc, DOCTOR INSTA, DocOnline, and
In selected apps, 144 were found to be ineligible These excluded health apps were providing the following services:

- Diet and fitness-related: 70

- Health information-related: 26

- Health insurance-related: 17

- Medicine order/information: 16

- Health programme-related: 8

- Hospital/lab/clinic locator: 4

- Others/unclassifiable: $\mathbf{3}$
In total, the $\mathbf{2 2}$ mobile health apps included in the study were providing online doctor consultation and/or doctor appointment booking-related services in India
Figure 1. Flowchart showing selection of mHealth applications. 
India Dental World apps. Among the 22 selected mHealth apps operating in India, Practo, mfine, DocsApp, 1mg, Netmeds, Lybrate, MediBuddy, and Medlife were found to be the eight most popular ones with over a million downloads and on average four-plus user rating out of five. Practo, mfine, and Lybrate offer doctor consultation through chat, audio, and video calling. Netmeds and DocsApp offer doctor consultation through both chat and audio call. $1 \mathrm{mg}$ offers free chat consultation, while MediBuddy and Medlife offer audio call consultation only. Practo, mfine, Netmeds, Lybrate, MediBuddy, and DocsApp charge a consultation fee for doctor consultation. Netmeds and mfine offer free follow-up consultation within 7 days of an initial consultation. Practo, mfine, DocsApp, Lybrate, MediBuddy, and Medlife provide an online health record maintenance facility, which $1 \mathrm{mg}$ and Netmeds do not offer. Considering booking doctor appointments for offline consultation, Practo, mfine, 1mg, and Lybrate only offer this facility among the eight most popular selected mHealth apps. In Lybrate, after the app has been downloaded, the app asks for background details of the patient, such as gender, age, marital status, height, weight, and existing health conditions to suggest a specialist who should be consulted to address the patient's given health condition. Practo offers various membership plans for healthcare in which a consumer must pay a certain amount initially to receive unlimited online consultations, free inclinic consultation, health check-ups, and medicine discount for a certain period of time. The mfine app provides the first doctor consultation for free. MediBuddy tracks the GPS location of the mobile subscriber to suggest nearby doctors of various specialities available for appointment booking with time and date slots. DocsApp asks for age, gender, symptoms, and health concerns before suggesting a specialist to provide the appropriate care for a patient's needs. In Medlife, one can choose from various specialists available at a particular date and time for consultation. Netmeds offers doctor consultation through chat after the patient has paid an initial consultation fee. Various specialist consultations in addition to the consultations by a general practitioner provided by these apps include gynaecology, dermatology, urology, dentistry, gastroenterology, paediatrics, oncology, sexology, endocrinology, nutrition, physiotherapy, psychiatry, general medicine, surgery, diabetology, pulmonology, cardiology, orthopaedics, and neurology among others (Table 1, Figure 2).

\section{Discussion}

\section{Challenges in Doctor Consultation through mHealth in India}

Although the accessibility of mobile phones and the internet has remarkably increased in the country in the last decade, it is still inaccessible to the bulk of the population. The major reasons are affordability and health literacy. More than one-fifth (21.9\%) of the population is still below the poverty line (BPL) [16]. These modern mHealth apps run on smartphones, which are often expensive. For a BPL family, earning a daily livelihood is the major challenge. Buying a smartphone is nothing more than daydreaming for them. On the other hand, existing literature regarding health literacy in India indicates that it is still low in the people of the country [17]. Those who have the financial capacity to buy a smartphone lack health literacy to make full use of these mHealth apps, and health literacy is one of the major determinants of healthcare utilisation in the country $[18,19]$.

\section{The Way Forward}

Healthcare delivery through a mobile app is a new concept in the healthcare delivery system of India, which is gradually likely be inculcated within it due to its high convenience and potential. In India, there is a very serious lack of healthcare infrastructure and trained health workers, especially in rural and suburban areas. India is home for 1.24 billion people, with about $70 \%$ of its people living in remote rural areas without adequate healthcare infrastructure. With merely 3.8\% GDP share allocated to healthcare, the Indian government, even after all positive intentions, cannot provide quality healthcare to its rural population overnight $[14,20]$. The process of healthcare infrastructure building is costly and lengthy. With the continuous growth of the mobile industry and growing teledensity in rural India, a large number of people in rural India have gained access to mobile phones [4]. This leaves us with an excellent opportunity to provide quality healthcare service using the mHealth platform. A healthy rural population is an asset for any nation, especially for countries like India, where the majority of the people live in remote rural areas. Moreover, it is a basic right of every citizen of the country to have good healthcare facilities at affordable rates. Using mHealth app consultations, travelling and time-related costs can be minimized for both users and providers. The platform may be used to raise the health literacy of the people of the country to improve their healthseeking behaviour. On the other hand, most of the doctors and nurses in the country are reluctant to work in rural ar- 
Table 1. Checklist showing distribution of selected mHealth apps operating in India and the range of services provided by them

\begin{tabular}{|c|c|c|c|c|c|c|c|}
\hline \multirow{2}{*}{ App name and web link } & \multicolumn{7}{|c|}{ Service provided } \\
\hline & CDO & $\mathrm{BDA}$ & BLT & BMO & $\mathrm{PHI}$ & PMI & MHR \\
\hline $\begin{array}{l}\text { Practo } \\
\text { http://bit.ly/21DVFXF }\end{array}$ & $\checkmark$ & $\checkmark$ & $\checkmark$ & $\checkmark$ & $\checkmark$ & - & $\checkmark$ \\
\hline $\begin{array}{l}\text { mfine } \\
\underline{\text { http://bit.ly/2lw19Xa }}\end{array}$ & $\checkmark$ & $\checkmark$ & $\checkmark$ & $\checkmark$ & - & - & $\checkmark$ \\
\hline $\begin{array}{l}\text { DocsApp } \\
\text { http://bit.ly/21ZvR8N }\end{array}$ & $\checkmark$ & - & $\checkmark$ & - & $\checkmark$ & - & $\checkmark$ \\
\hline $\begin{array}{l}1 \mathrm{mg} \\
\underline{\mathrm{http}: / / \mathrm{bit} .1 \mathrm{ly} / 2 \mathrm{k} 2 \mathrm{InDS}}\end{array}$ & $\checkmark$ & - & $\checkmark$ & $\checkmark$ & $\checkmark$ & $\checkmark$ & - \\
\hline $\begin{array}{l}\text { Netmeds } \\
\underline{\text { http://bit.ly/2m0sXkb }}\end{array}$ & $\checkmark$ & - & - & $\checkmark$ & $\checkmark$ & - & - \\
\hline $\begin{array}{l}\text { Lybrate } \\
\underline{\text { http://bit.ly/2kuBQSD }}\end{array}$ & $\checkmark$ & $\checkmark$ & $\checkmark$ & - & $\checkmark$ & - & $\checkmark$ \\
\hline $\begin{array}{l}\text { MediBuddy } \\
\underline{\text { http://bit.ly/21YsPSe }}\end{array}$ & $\checkmark$ & - & $\checkmark$ & $\checkmark$ & - & - & - \\
\hline $\begin{array}{l}\text { Medlife } \\
\text { http://bit.ly/2ktWgLn }\end{array}$ & $\checkmark$ & - & $\checkmark$ & $\checkmark$ & - & - & $\checkmark$ \\
\hline $\begin{array}{l}\text { Ask Apollo } \\
\text { http://bit.ly/2ksBpbi }\end{array}$ & $\checkmark$ & $\checkmark$ & $\checkmark$ & $\checkmark$ & - & - & $\checkmark$ \\
\hline $\begin{array}{l}\text { India Health Line } \\
\text { http://bit.ly/2lxnYHm }\end{array}$ & $\checkmark$ & - & - & $\checkmark$ & - & - & - \\
\hline $\begin{array}{l}\text { Lifecare Health } \\
\underline{\text { http://bit.ly/2m0tB15 }}\end{array}$ & $\checkmark$ & - & $\checkmark$ & - & $\checkmark$ & - & - \\
\hline $\begin{array}{l}\text { Visit-Free Chat with a Doctor } \\
\text { http://bit.ly/2ki0DcE }\end{array}$ & $\checkmark$ & - & $\checkmark$ & $\checkmark$ & - & - & - \\
\hline $\begin{array}{l}\text { I Online Doctor } \\
\underline{\text { http://bit.ly/2m0v1IX }}\end{array}$ & $\checkmark$ & $\checkmark$ & - & - & - & $\checkmark$ & $\checkmark$ \\
\hline $\begin{array}{l}\text { Ask a Doctor } \\
\text { http://bit.ly/2jYtnGX }\end{array}$ & $\checkmark$ & - & - & - & $\checkmark$ & - & - \\
\hline $\begin{array}{l}\text { docOPD } \\
\underline{\text { http://bit.ly/2ksyv6w }}\end{array}$ & $\checkmark$ & - & $\checkmark$ & - & - & - & - \\
\hline $\begin{array}{l}\text { ML Xpress } \\
\underline{\text { http://bit.ly/2lx4jr4 }}\end{array}$ & $\checkmark$ & - & - & $\checkmark$ & - & - & - \\
\hline $\begin{array}{l}\text { CallDoc App } \\
\underline{\text { http://bit.ly/2k4jgAE }}\end{array}$ & - & $\checkmark$ & - & - & $\checkmark$ & - & $\checkmark$ \\
\hline $\begin{array}{l}\text { DOCTOR INSTA } \\
\underline{\text { http://bit.ly/2kt4e7E }}\end{array}$ & $\checkmark$ & $\checkmark$ & $\checkmark$ & $\checkmark$ & - & - & - \\
\hline $\begin{array}{l}\text { vHealth by Aetna } \\
\underline{\text { http://bit.ly/2lvyNd } 9}\end{array}$ & $\checkmark$ & - & - & - & - & - & - \\
\hline $\begin{array}{l}\text { WayuMD } \\
\underline{\text { http://bit.ly/21ZxG5D }}\end{array}$ & $\checkmark$ & - & - & - & - & - & $\checkmark$ \\
\hline $\begin{array}{l}\text { DocOnline } \\
\underline{\text { http://bit.ly/2kuCOOL }}\end{array}$ & $\checkmark$ & $\checkmark$ & - & - & - & - & $\checkmark$ \\
\hline $\begin{array}{l}\text { India Dental World } \\
\text { http://bit.ly/21CKqz2 }\end{array}$ & $\checkmark$ & $\checkmark$ & - & - & $\checkmark$ & - & - \\
\hline
\end{tabular}

CDO: consult doctors online, BDA: book doctor's appointment, BLT: book lab tests, BMO: book medicine online, PHI: provide health information, PMI: provide medicine information, MHR: manage health records. 


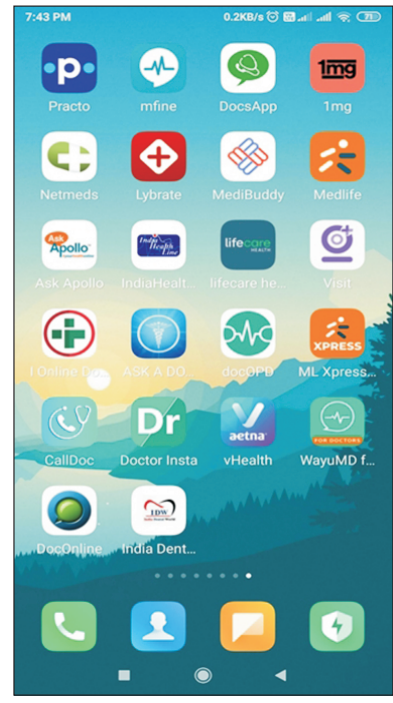

Figure 2. Screenshot of selected mHealth applications.

eas primarily due to low living standards, as well as limited learning opportunities, career growth, and earning opportunities there compared to urban areas [21,22]. The government, with the current spending in healthcare, will take decades to create a traditional health infrastructure to meet the healthcare needs of its people. On the other hand, mHealth only requires awareness, minimal funding, and planning by the government. Thus, gradually, it may evolve as a suitable alternative to reach the person living in the remotest location of the country with quality healthcare at an affordable rate.

To conclude, among the selected mHealth apps providing doctor consultation services online/offline and operating in India, Practo, mfine, DocsApp, 1mg, Netmeds, Lybrate, MediBuddy, and Medlife were found to be the eight most popular ones with over a million downloads and on average four-plus user rating out of five. The government should make enabling policies to facilitate and popularise mHealth applications in the country.

\section{Conflict of Interest}

No potential conflict of interest relevant to this article was reported.

\section{ORCID}

Neeraj Agarwal (http://orcid.org/0000-0002-8526-0164)

Bijit Biswas (http://orcid.org/0000-0002-7609-6446)

\section{References}

1. World Health Organization. mHealth: New horizons for health through mobile technologies: second global survey on eHealth [Internet]. Geneva, Switzerland: World Health Organization; 2011 [cited at 2020 Apr 1]. Available from: https://www.who.int/goe/publications/goe mhealth_web.pdf.

2. Tomlinson M, Rotheram-Borus MJ, Swartz L, Tsai AC. Scaling up mHealth: where is the evidence? PLoS Med 2013;10(2):e1001382.

3. International Telecommunication Union. Measuring the Information Society Report 2018 [Internet]. Geneva, Switzerland: International Telecommunication Union; 2018 [cited at 2020 Apr 1]. Available from: https:// www.itu.int/en/ITU-D/Statistics/Pages/publications/ misr2018.aspx.

4. Telecom Regulatory Authority of India. Wireless data services in India: an analytical report [Internet]. New Delhi, India: Government of India; 2018 [cited at 2020 Apr 1]. Available from: https://main.trai.gov.in/sites/default/files/Wireless_Data_Service_Report_21082019_0. pdf.

5. Kashgary A, Alsolaimani R, Mosli M, Faraj S. The role of mobile devices in doctor-patient communication: a systematic review and meta-analysis. J Telemed Telecare 2017;23(8):693-700.

6. Hsieh CH, Tsai HH, Yin JW, Chen CY, Yang JC, Jeng SF. Teleconsultation with the mobile camera-phone in digital soft-tissue injury: a feasibility study. Plast Reconstr Surg 2004;114(7):1776-82.

7. Mitchell M, Lesh N, Cranmer H, Fraser H, Haivas I, Wolf K. Improving care-improving access: the use of electronic decision support with AIDS patients in South Africa. Int J Healthc Technol Manag 2009;10(3):156-68.

8. Garets D, Davis M. Electronic medical records vs. electronic health records: yes, there is a difference [Internet]. Chicago (IL): HIMSS Analytics; 2006 [cited at 2020 Apr 1]. Available from: https://www.tehandassociates.com/ wp-content/uploads/2017/03/WP_EMR_EHR.pdf.

9. Patrick K, Griswold WG, Raab F, Intille SS. Health and the mobile phone. Am J Prev Med 2008;35(2):177-81.

10. Martins HM, Jones MR. What's so different about mobile information communication technologies (MICTs) for clinical work practices? A review of selected pilot studies. Health Inform J 2005;11(2):123-34.

11. Iribarren SJ, Cato K, Falzon L, Stone PW. What is the economic evidence for mHealth? A systematic review of 
economic evaluations of mHealth solutions. PLoS One 2017;12(2):e0170581.

12. de la Torre-Diez I, Lopez-Coronado M, Vaca C, Aguado JS, de Castro C. Cost-utility and cost-effectiveness studies of telemedicine, electronic, and mobile health systems in the literature: a systematic review. Telemed J E Health 2015;21(2):81-5.

13. Ivatury G, Moore J, Bloch A. A doctor in your pocket: health hotlines in developing countries. Innovations 2009;4(1):119-53.

14. Ministry of Health \& Family Welfare, National Health Systems Resource Centre. National Health AccountsEstimates for India-2015-16 [Internet]. New Delhi, India: Government of India; 2018 [cited at 2020 Apr 1]. Available from: http://nhsrcindia.org/updates/nationalhealth-accounts-estimates-india-2015-16.

15. Ahluwalia IJ. Challenges of urbanisation in India. In: Besley T, editor. Contemporary issues in development economics. London: Palgrave Macmillan; 2016. p. 16377.

16. Ministry of Statistics and Programme Implementation. India in figures 2018 [Internet]. New Delhi, India: Government of India; 2018 [cited at 2020 Apr 1]. Available from: http://mospi.nic.in/sites/default/files/publication_ reports/India_in_figures-2018_rev.pdf.

17. Barve SS, Joshi S. A literature review of measurement of health literacy in India. Indian J Public Health Res Dev
2019;10(5):724-9.

18. Johri M, Subramanian SV, Kone GK, Dudeja S, Chandra $\mathrm{D}$, Minoyan N, et al. Maternal health literacy is associated with early childhood nutritional status in India. J Nutr 2016;146(7):1402-10.

19. Ogorchukwu JM, Sekaran VC, Nair S, Ashok L. Mental health literacy among late adolescents in South India: what they know and what attitudes drive them. Indian J Psychol Med 2016;38(3):234-41.

20. Ministry of Home Affairs. Post Enumeration Survey Reports 2011 [Internet]. New Delhi, India: Government of India; 2011 [cited at 2020 Apr 1]. Available from: http:// censusindia.gov.in/2011Census/pes/pes_highlights. html.

21. World Health Organization. World health statistics 2016: monitoring health for the SDGs, sustainable development goals [Internet]. Geneva, Switzerland: World Health Organization; 2016 [cited at 2020 Apr 1]. Available from: https://apps.who.int/iris/handle/10665/206498.

22. Muralidharan K, Chaudhury N, Hammer J, Kremer M, Rogers FH. Is there a doctor in the house? Medical worker absence in India [Internet]. Cambridge (MA): Harvard University; 2011 [cited at $2020 \mathrm{Apr}$ 1]. Available from: http://www.hrhresourcecenter.org/ node/3964. 